East African Medical Journal Vol. 82 No. 3 March 2005

CALCIUM DEFICIENCY AND CAUSATION OF RICKETS IN ETHIOPIAN CHILDREN

T. Belachew, MD, MSc, DLSHTM, Nutritionist, H. Nida, MD, Paeditrician, T. Getaneh, MD, Paeditrician, D. Woldemariam, MD, MSc, Paeditrician, Epidemiologist and W. Getinet, MD, Radiologist, Jimma University Specialised Hospital, P. O. Box 1104, Jimma, Ethiopia

Request for reprints to: Dr. T. Belachew, P. O. Box 1104, Jimma, Ethiopia

\title{
CALCIUM DEFICIENCY AND CAUSATION OF RICKETS IN ETHIOPIAN CHILDREN
}

\author{
T. BELACHEW, H. NIDA, T. GETANEH, D. WOLDEMARIAM and W. GETINET
}

\begin{abstract}
Objective: To assess the role of calcium in the development of clinical rickets among Ethiopian children coming to Jimma Specialised Hospital outpatient, department. Design: Case control study.

Settings: Jimma Specialised Teaching Hospital and surrounding urban and rural community in the catchment area.

Subjects: One hundred and thirty five under five year old children (30 cases of rickets and 104 non-rachitic cases) who came for paediatric service in Jimma hospital.

Results: The mean $( \pm \mathrm{SD})$ level of calcium intake for cases and controls was 664.5 $( \pm 102.7) \mathrm{mg}$ and $645.8( \pm 144.4) \mathrm{mg}$, respectively. There was no statistically significance difference between the two groups in the mean level of calcium intake $(t=0.659$, $P>0.05)$. Generally, in both cases and controls the majority of the study participants were taking calcium below the recommended daily calcium requirement of $800 \mathrm{mg}$ for age group according to Food and Nutrition Board of the National Research Council. When adjusted for different co-variates including age, sex, breast feeding history, history of diarrhoea lasting longer than 14 days and 24 hours calcium intake children and religion, occupation, educational status and residence the mothers/care givers using logistic regression model, frequency of exposure to sunlight ( $\mathrm{OR}=1.55,95 \% \mathrm{CI}$ : 1.2, 2.0), being from rural areas $(O R=5.0,95 \%$ CI: 1.1, 23.3) and age 12-23 months $(O R=$ 4.5, 95\% CI: $1.2,16.5)$ were significantly associated with rickets( $P<0.05)$.

Conclusion: It was found that Ethiopian children with rickets and without had a low calcium intake as compared to the recommended daily allowance. The fact that there was no difference in the dietary calcium intake between cases and controls and the significant difference observed between case and controls in terms of frequency of exposure to sunlight per week reflects that vitamin D deficiency emanating from poor exposure to radiant energy is the main cause of rickets in Ethiopian children. This study also documented the fact that rural children are at a higher risk of developing rickets as compared to their urban counterparts which could be mainly due to the traditional beliefs and practices more prevalent in the rural areas. Enhancing behaviour change communication about the benefits of exposing children to sunlight is very important in preventing the prevalence of rickets.
\end{abstract}

\section{INTRODUCTION}

Rickets is the term signifying a failure in mineralisation of growing bone or osteoid tissue. During the first third part of this century, the predominant cause of rickets was nutritional deficiency of vitamin D due either to inadequate direct exposure to ultraviolet rays in sunlight (296-310 nm; these rays do not pass through ordinary window glass) or to inadequate intake of vitamin $\mathrm{D}$, or both. However, its clinical significance is mainly due to the effect the disease has on child health in general. Developmental delay is a commonly observed finding in rickets so much so that it is considered part of the clinical spectrum of the disease. Moreover, rickets is associated with increased morbidity and mortality. There is ample evidence demonstrating increased rates of infections, particularly diarrhoeal diseases (1) and acute respiratory infections (1-5), in rachitic children. An increased susceptibility to infection may be multifactorial. The chest wall deformity of late rickets, altered immune status and the association of rickets with proteinenergy malnutrition (PEM) are some of the factors involved $(3,5)$. Rickets also contributes to increased mortality. In a case-control study done in Addis Ababa it was found that the odds of dying in rachitic patients was five times higher than that of controls (3). 
Paradoxically, rickets is widely prevalent in many tropical and subtropical regions despite abundant sunshine (6). Reports from health institutions suggest that rickets is an important child health problem in Ethiopia (3,7, 8). A review of paediatric admissions in Jimma hospital indicated that about $7 \%$ of children aged less than five years were diagnosed to have rickets (8). A more recent community based study in Jimma town showed rickets prevalence of $4 \%$ in randomly selected children between 6-59 months of age (2).

Vitamin D deficiency is the commonest cause of rickets in children and vitamin D supplementation has brought down the incidence of rickets to a virtually nonexistent level in the developed world. The infant with rickets in the United States, for instance, is typically a black breastfed infant who did not receive supplemental vitamin D (9). In developing countries where there is a high proportion of sunny weather the occurrence of rickets in a significant proportion of children is largely attributed to social and cultural factors. Keeping children indoors due to fear that they will catch cold, fear of evil eyes, and the tradition of wrapping children in swaddling clothes contribute to lack of adequate sunlight exposure $(1,10)$. The incidence of rickets is particularly high in slum children who live in crowded houses almost devoid of sunlight (6).

A study done in Addis Ababa in the 1960's showed that nearly half of the rachitic children had been carefully protected against sunshine (7). Similar observations as well as the good clinical response to vitamin $\mathrm{D}$ is the basis for incriminating vitamin $\mathrm{D}$ deficiency as the most common cause of rickets in Ethiopia. Contrary to expectations a recent study conducted in Jimma failed to show an association between sunlight exposure and rickets. All the rachitic children were said to be exposed to sunlight, the majority daily, and with no clothes on (2). Parents who may be aware of the desired response could probably give history of exposure to sunlight hence introducing bias. On the other hand, it is also possible that other factors are contributing to the development of rickets. The most probable alternative explanation for the lack of association between rickets and exposure to sunlight is reduced dietary intake of calcium as a major factor in the causation of rickets. Several studies and reports have documented the fact that calcium deficiency could lead to rickets (11-16). The deficiency of calcium may increase the requirement for vitamin $\mathrm{D}$, and therefore calcium deficiency may aggravate a borderline vitamin $\mathrm{D}$ status. In rats the rate of inactivation of 25hydioxycholecalciferol (25-OHD) in the liver is increased by calcium deprivation (or increased phytic acid). The effect is mediated by 1,25 dihydroxy-cholecalciferol $(1,25$ (OH)2D) produced in response to secondary hyperparathyroidism(13). Studies conducted in Nigeria suggest that rickets is largely the result of lack of calcium deficiency $(14,15)$. Calcium deficiency as a cause of rickets is also reported from rural South Africa (16). The evidence for the role of calcium deficiency in the causation of rickets comes from dietary surveys, biochemical studies, and the response to calcium therapy alone. We hypothesised that low dietary calcium intake may contribute to the development of rickets in Ethiopian children. So far studies looking at the role of calcium deficiency in rickets have not been conducted in Ethiopia. Therefore, this study assessed the differences in sunlight exposure and calcium intake in the rachitic and non-rachitic children in Jimma specialised hospital paediatric out-patient department.

\section{MATERIALS AND METHODS}

The study was conducted in Jimma University Specialised Hospital and a case-control design was employed. The sample size was calculated by using the EPI-info version-2000 and set at $95 \%$ confidence and power of $80 \%$. A physician who had experience in handling children examined all the cases and controls for signs of rickets and a radiologist read the $\mathrm{X}$-rays. Cases were identified based on the confirmation of the diagnosis of rickets clinically and radiologically. Definition of cases and controls was made as follows: Cases were, defined by the presence of two or more clinical signs (rachitic rosaries, chest wall deformity, frontal bossing, wide anterior fontanel, craniotabes, caput quadratum wide wrist and double maleoli), and radiological evidence of rickets, i.e., cupping and fraying of the ends of the ulna and radius, and widening of the epiphysis, on wrist X-ray. Children who had no clinical signs of rickets were selected as controls. Clinically normal subjects did not undergo further radiological diagnosis i.e., rickets was excluded in the control group by clinical examination alone.

All children with rickets (cases) seen in Jimma hospital paediatric outpatient or admitted in the children's wards were enrolled in the study after informed consent was obtained from the child's guardian. Age and sex matched non-rachitic children were taken as control based on a clinical confirmation of the absence signs of rickets by a physician. Interviewer administered structured questionnaire and twenty four hours dietary recall methods were used to collect dietary data and data on the other socio-demographic characteristics which include: age, sex, address, family income, parental literacy status, occupation, history of exposure to sunlight from birth to the current age: age at first exposure, frequency of exposure, duration of exposure at each sitting, condition of clothing during exposure, breast feeding, weight and length/ height. A trained health worker who speaks the local language (Oromiffa) filled the questionnaire.

Using food-composition tables designed for Ethiopian cooked and raw food stuffs, $(32,33)$ dietary calcium intake was calculated by asking parents or guardians about the children's food intake on the preceding day ( 24 hours period). The twotailed Student's t-test for independent samples was used to compare mean values of calcium intake between children with rickets and matched control children.

The investigators checked the progress of the data collection and quality of data. The data were cleaned, edited and entered into a computer and analysed using SPSS for windows version 11.0. Logistic regression analysis was done to delineate factors which are independently associated with rickets. Statistical tests were performed at the level of significance of 0.05 .

All cases and controls were enrolled in the study after the guardians were informed about the purpose of the study, the type of investigations to be carried out, the inconvenience 
that the study entails and the fact that failure of participation does not in any way affect the child's treatment. The radiological results were made available to the treating physician. A single exposure to radiation for wrist X-ray causes minimal or no health risk. Moreover, as X-ray examination is an established diagnostic test for rickets many would have undergone the test even if they were not part of the study. To minimise the risk of exposure, a wrist $\mathrm{X}$-ray was not taken in a child who has a chest X-ray for a different reason (e.g. as part of a work-up for pneumonia) so long as the proximal humerus was visible on the film. Children with rickets were treated.

The controls, on the other hand, were children who were free of rickets clinically and they were not X-rayed for the purpose of the study. The proposal was submitted to the ethical Clearance Committee of Jimma University, to the medical director of Jimma hospital, and to the department of paediatrics for approval. The limitations of the study were that as it was conducted in Jimma hospital the findings of the study may not be generalized to the country at large. The dietary calcium intake was estimated using 24-hour dietary recall method, which gives at best a rough estimate of the mean calcium intake of the two groups. Other tests such as the urinary calcium excretion, the serum vitamin $\mathrm{D}$, and parathyroid levels would have been useful in providing more accurate information on the importance of calcium deficiency in children with rickets. However, these tests were not available to the investigators.

\section{RESULTS}

A total of 30 cases and 104 controls were involved in the study out of which 87 were males and 47 were females giving a sex ratio of 1.9:1. The mean age of cases and controls were 13.3 and 13.4, respectively. The baseline characteristics of the two groups of children are shown in 2. There was no significant difference between children with rickets and the control children in terms of their nutritional status and other background variables like place of residence, literacy status, religion, occupation of the care takers and sex, age and history of breastfeeding of children $(\mathrm{P}>0.05$. However, there was a statistically significant difference $(\mathrm{P}=0.000)$ between the cases and controls in the frequency of exposure to direct sunlight per week.
Figure 1

Trend of rickets by the frequency of exposure to sunlight per week among the study participants

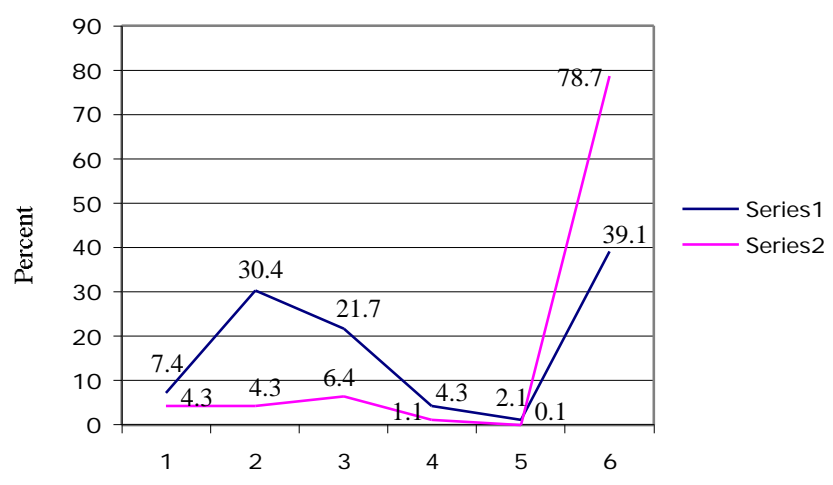

Frequency of exposure to sunlight per week

Rickets cases

Controls

The majority $84(64 \%)$ of the study subjects were from the urban areas and the rest were from the rural community. Over half of the subjects were Muslim by religion and the majority were Oromo by ethnicity. Regarding their occupation, large proportion of subjects were housewives followed by government employees. Most of the study subjects had educational status of primary level and below (Table 2). The mean (+SD) level of calcium intake for cases and controls was 664.5 $( \pm 102.7) \mathrm{mg}$ and $645.8( \pm 144.4) \mathrm{mg}$, respectively which was well below the daily allowance of $800 \mathrm{mg}$ recommended by the Nutrition Board of the National Research Council, 1989 (Table 1). There was no statistically significance difference between the two groups in the mean level of calcium intake $(t=0.659, \mathrm{P}>0.05)$.

The majority of both cases and controls had daily calcium intake below $800 \mathrm{mg}$ recommended for age group according to Food and Nutrition Board of the National Research Council.

Table 1

Mean twenty four hours dietary calcium intake in cases of rickets and controls

\begin{tabular}{llllll}
\hline Category & Number & Mean Cal. intake(Mg) & Std Dev. & t-test & P- value \\
\hline Cases & 30 & 664.5 & 102.7 & 0.659 & 0.096 \\
Controls & 104 & 645.8 & 144.4 & & \\
\hline
\end{tabular}


Table 2

Background characteristics of study subjects with and without rickets

\begin{tabular}{|c|c|c|c|}
\hline Characteristics Background & $\begin{array}{l}\text { Cases }(\mathrm{n}=30) \\
\text { No. }(\%)\end{array}$ & $\begin{array}{l}\text { Controls }(n=104) \\
\text { No. }(\%)\end{array}$ & P-value \\
\hline Age Group (Months) & & & 0.68 \\
\hline $0-11$ & $16(53.3)$ & $46(44.2)$ & \\
\hline $12-23$ & $12(40.0)$ & $50(48.1)$ & \\
\hline $24-48$ & $2(6.7)$ & $8(7.7)$ & \\
\hline Total & $30(100)$ & $104(100)$ & \\
\hline \multicolumn{4}{|l|}{ Sex } \\
\hline Male & $20(66.7)$ & $67(64.4)$ & 0.82 \\
\hline Female & $10(33.3)$ & $37(35.6)$ & \\
\hline Total & $30(100)$ & $104(100)$ & \\
\hline \multicolumn{4}{|l|}{ Residence } \\
\hline Urban & $21(70.0)$ & $63(60.6)$ & 0.35 \\
\hline Rural & $9(30.0)$ & $41(39.4)$ & \\
\hline Total & $30(100)$ & $104(100)$ & \\
\hline \multicolumn{4}{|l|}{ Religion } \\
\hline Christian & $16(53.0)$ & $45(43.3)$ & 0.26 \\
\hline Muslim & $14(47.0)$ & $59(56.7)$ & \\
\hline Total & $30(100)$ & $104(100)$ & \\
\hline \multicolumn{4}{|l|}{ Breast feeding } \\
\hline Yes & $29(96.7)$ & $98(94.2)$ & \\
\hline No & $1(3.3)$ & $6(5.8)$ & 0.60 \\
\hline Total & $30(100)$ & $104(100)$ & \\
\hline Occupation (mother) & & & 0.60 \\
\hline Government employee & $23(76.7)$ & $84(80.8)$ & \\
\hline Private employee & $5(17.7)$ & $6(5.8)$ & \\
\hline Other & $2(6.7)$ & $15(14.2)$ & \\
\hline Total & $30(100)$ & $104(100)$ & \\
\hline Literacy status (Mother) & & & 0.23 \\
\hline Illiterate & $10(37.0)$ & $45(46.9)$ & \\
\hline Primary & $11(407)$ & $33(34.4)$ & \\
\hline Secondary & $4(14.8)$ & $17(17.7)$ & \\
\hline Above secondary & $3(7.4)$ & $9(1.0)$ & \\
\hline Total & $30(100)$ & $104(100)$ & \\
\hline Frequency of direct sunlight exposure & & & 0.000 \\
\hline per week & $15(50.0)$ & $21(20.2)$ & \\
\hline $1-2$ & $6(20.0)$ & $7(6.7)$ & \\
\hline $3-4$ & $9(30.0)$ & $76(73.0)$ & \\
\hline >or $=5$ & $30(100)$ & $104(100)$ & \\
\hline \multicolumn{4}{|l|}{ Diarrhoea lasting $>14$ days } \\
\hline Yes & $20(66.7)$ & $60(57.8)$ & \\
\hline No & $10(33.3)$ & $44(42.3)$ & 0.41 \\
\hline Total & $30(100)$ & $104(100)$ & \\
\hline 24 hrs dietary calcium intake & $2(6.7)$ & $12(11.5)$ & 0.34 \\
\hline$>=$ RDA & $28(96.6)$ & $92(88.5)$ & \\
\hline$<$ RDA & $30(100)$ & $104(100)$ & \\
\hline Nutritional Status & 1343.3 & & \\
\hline Normal & $17(56.7)$ & $44(42.3)$ & 0.92 \\
\hline Malnourished & $30(100)$ & $60(100)$ & \\
\hline Total & & $104(100)$ & \\
\hline
\end{tabular}


Table 3

Adjusted odds ratio of different co-variate variables with cases and controls

\begin{tabular}{|c|c|c|c|c|c|}
\hline \multirow[t]{2}{*}{ Co-variate } & \multirow{2}{*}{$\begin{array}{l}\text { Cases }(n=104) \\
\text { No. }(\%)\end{array}$} & \multirow{2}{*}{$\begin{array}{l}\text { Controls }(\mathrm{n}=104) \\
\text { No. }(\%)\end{array}$} & \multirow{2}{*}{$\begin{array}{l}\text { Adjusted Odds } \\
\text { Ratio }\end{array}$} & \multicolumn{2}{|l|}{$95.0 \% \mathrm{CI}$} \\
\hline & & & & Lower & Upper \\
\hline \multicolumn{6}{|l|}{ Age (Months) } \\
\hline $0-11 *$ & $16(53.3)$ & $46(44.2)$ & & & \\
\hline $12-23$ & $12(40.0)$ & $50(48.1)$ & $4.516 * *$ & 1.236 & 16.501 \\
\hline $24-48 *$ & $2(6.7)$ & $8(7.7)$ & & & \\
\hline \multicolumn{6}{|l|}{$\begin{array}{l}\text { Educational status } \\
\text { of the mother }\end{array}$} \\
\hline illiterate & $10(37.0)$ & $45(46.9)$ & 0.543 & 0.066 & 4.491 \\
\hline Primary & $11(40.7)$ & $33(34.4)$ & 1.481 & 0.163 & 13.467 \\
\hline Secondary & $4(14.8)$ & 17 (17.7) & 3.367 & 0.253 & 44.742 \\
\hline Above & $3(7.4)$ & $9(1.0)$ & & & \\
\hline \multicolumn{6}{|l|}{ Secondary* } \\
\hline Diarrhoea during the last & & & 2.958 & 0.821 & 10.656 \\
\hline two weeks & $20(66.7)$ & $60(58.3)$ & & & \\
\hline Yes & $10(33.3)$ & $44(41.7)$ & & & \\
\hline \multicolumn{6}{|l|}{ No* } \\
\hline Occupation of the mother & & & 0.393 & 0.041 & 3.813 \\
\hline Government employee & $23(76.7)$ & $84(80.8)$ & & & \\
\hline Private employee & $5(17.7)$ & $6(5.8)$ & 1.53 & 0.000 & 9.30 \\
\hline Other* & $2(6.7)$ & $15(14.2)$ & & & \\
\hline Religion & & & 1.344 & 0.414 & 4.358 \\
\hline Christian & $16(53.0)$ & $45(72.4)$ & & & \\
\hline Muslim* & $14(47.0)$ & $59(80.9)$ & & & \\
\hline \multicolumn{6}{|l|}{ Residence } \\
\hline Rural & $21(70.0)$ & $63(60.6)$ & $5.058 * *$ & 1.103 & 23.189 \\
\hline Urban* & $9(30.0)$ & $41(39.4)$ & & & \\
\hline \multicolumn{6}{|l|}{ Sex } \\
\hline Male* & $20(66.7)$ & $67(64.4)$ & 0.585 & 0.177 & 1.934 \\
\hline Female* & $10(33.3)$ & $37(35.6)$ & & & \\
\hline \multicolumn{6}{|l|}{ Breast feeding } \\
\hline Yes & $29(96.7)$ & $98(94.2)$ & 001 & 0.000 & 48.145 \\
\hline $\mathrm{No}^{*}$ & $1(3.3)$ & $6(5.8)$ & & & \\
\hline \multicolumn{6}{|l|}{24 hours calcium intake } \\
\hline$>=\mathrm{RDA}$ & $2(6.7)$ & $12(11.5)$ & 0.994 & 0.989 & 1.000 \\
\hline$<=\mathrm{RDA}$ & $28(93.3)$ & $91(88.5)$ & & & \\
\hline \multicolumn{6}{|l|}{$\begin{array}{l}\text { Frequency of exposure to } \\
\text { direct sunlight per week }\end{array}$} \\
\hline $1-2$ & $15(50.0)$ & $21(20.2)$ & $1.548 * *$ & 1.199 & 2.000 \\
\hline $3-4$ & $6(20.0)$ & $7(6.7)$ & & & \\
\hline$>$ or $=5$ & $9(30.0)$ & $76(73.0)$ & & & \\
\hline
\end{tabular}

* Referent categories, ** statistically significant at the level of significance of 0.05 .

Figure 2

Trend of duration of exclusive breast feeding among ricket cases and controls

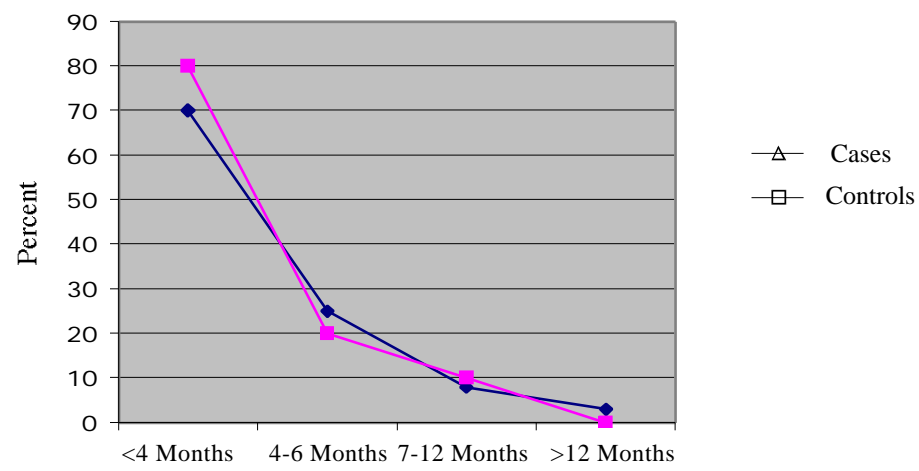


It was observed that the trend of exclusive breastfeeding was similar for cases and controls. In both cases exclusive breast-feeding had continued beyond six months, which is not nutritionally adequate for normal growth of infants (Figure 2). Using a logistic regression model, when adjusted for different co-variates including age, sex, breastfeeding, diarrhoea lasting greater than 14 days and 24 hours calcium intake of children and religion, occupation, educational status and residence of the mother/care givers, frequency of exposure to sunlight of children per week, $(\mathrm{OR}=1.55,95 \% \mathrm{CI}$ : 1.2 , 2.0), being from rural areas $(\mathrm{OR}=5.0,95 \% \mathrm{CI}$ : 1.1 , 23.3) and age 12-23 months $(\mathrm{OR}=4.5$, 95\%CI: 1.2 , $16.5)$ were significantly $(\mathrm{P}<0.05)$ associated with rickets, respectively (Table 3 ).

\section{DISCUSSION}

Overall 30 cases, which had radiologically, and clinically confirmed rickets and 104 controls were enrolled in the study. In a country where there is thirteen months of sunshine the existing higher prevalence of rickets seems paradoxical and catches an attention of researchers and health care providers. Nutritional rickets in children is usually considered to be due primarily to a deficiency of vitamin $\mathrm{D}$, but several small studies in tropical and sub tropical countries (Nigeria and South Africa) have suggested that in these countries, a low dietary intake of calcium has an important role. These studies reported that children with rickets had a response to calcium therapy $(15,16,20,21)$. Another study in Nigeria reported that calcium supplementation with or without vitamin D therapy was more effective than supplementation with vitamin $\mathrm{D}$ alone in healing active rickets in a cohort of Nigerian children (23).

It was with this scenario in place that the current study was conducted in the Ethiopian context. In the current study it was observed that there was no significant difference in the mean 24 hours dietary calcium intake between cases of rickets and the controls ( $T=0.659$, $\mathrm{P}>0.05)$, which is similar to the finding of a study in Nigeria (23). Most of the cases of rickets and the controls have marginal calcium intake as compared to the recommended daily allowance $(800 \mathrm{mg} /$ day) for the age group and Nutrition Board of the National Research Council, 1989. Regarding the breast milk intake of the cases and controls similar pattern was observed in the trend of exlusive breast feeding in both groups showing that there was no difference in the calcium intake of both groups from breast milk as well.

The absence of a difference in dietary calcium intake between the children with rickets and the control children may imply that a low calcium intake alone cannot by itself be a cause for rickets. When adjusted for other co-variates using a binary logistic regression model, frequency of exposure to direct sun light per week was found to be strongly associated with development of rickets in the cases. It was observed that the control group of children were exposed to sun light more frequently as compared to the cases of rickets $(\mathrm{P}<0.05)$. Cases not exposed to sunlight more frequently were 1.6 times more likely to develop rickets as compared to the controls which were exposed. Frequency of exposure to direct sunlight was lower among cases of rickets as compared to controls.

The skin has a large capacity to produce vitamin D. Exposure of the entire body to the smallest amount of ultra $\mathrm{B}(\mathrm{UVB})$ radiation that produces transient just perceptible skin reddening is comparable to taking an oral dose of 10,000 to 25,000 IU of vitamin $\mathrm{D}(24,28,29)$. Therefore, sufficient levels of vitamin D can be developed from partial exposure of the body to sunlight well before sunburn occurs. The age at onset of rickets resulting from a deficiency of vitamin $\mathrm{D}$ peaks between 4 and 12 months (19) whereas the age at onset of rickets among Ethiopian children was from 12-23 months which is similar to the findings of a study in Nigeria which showed a package of rickets to be between 15 and 25 months (23).

According to this study children in the age group 12-23 months were 4.5 times more likely to develop rickets as compared to the other age groups. This may be due to the reason that this age group is not getting adequate sunlight exposure and also may not be on breast feeding which is a very good source of calcium. There is a possibility that vitamin D deficiency could lead to rickets in younger children, whereas a deficiency of calcium could be the chief factor in sustaining the disease in older children (18). However, in another study no correlation was found between serum 25hydroxyvitamin D concentrations and age to support this possibility (23). Research has shown that human milk contains adequate vitamin $\mathrm{D}$ for at least the first six months of life. According to La Leche League International, the world's recognised authority on breastfeeding, rickets has rarely been found in fully breastfed infants. This is true even in northern climates where there is less exposure to sunlight, which activates the formation of vitamin D.

Children from the rural areas were also five times more likely to develop rickets as compared to the urban children. Rural children are more likely to be less exposed to sunlight due to different traditional beliefs and practices associated with it. Mothers fear evil eyes and also sunburn('Mich") and keep the infants and young children at home or get them stuffed with clothes preventing them from direct sun light exposure. Concern is directed to, infants whose mothers cover them up due to cultural beliefs and/or do not eat dairy products. or supplement their diets with foods or vitamins containing vitamin D.

Research suggests that people who wear enveloping clothing should expose their babies' uncovered cheeks to sunlight for just 20 minutes a day to get the needed vitamin D. Because the biologically normal means of obtaining sufficient vitamin D in humans is via sunlight exposure not diet (25-27). Lack of exposure to sunlight resulting from less time being spent outdoors is the cause of the increase in incidence of rickets. vitamin $\mathrm{D}$ is a 
hormone that our bodies metabolise from the sun. The amount of sunlight needed to maintain normal vitamin D levels is approximately 30 minutes a week in an infant wearing only a diaper, or 2 hours a week in a clothed infant (24).

Knowledge concerning the pathogenesis of rickets in children in developing countries in tropical and subtropical region has considerable public health significance and forms the basis for preventive public health programmes. In a tropical country like ours with plenty of sunlight as source of vitamin D, cultural factors may be the only cause of rickets in a number of cases. In conclusion, we found that Ethiopian children with rickets and without had a low calcium intake as compared to the recommended daily allowance. The fact that there was no difference in the dietary calcium intake between cases and controls and the significant difference observed between cases and controls in terms of frequency of exposure to sunlight per week reflects that vitamin D deficiency emanating from poor exposure to radiant energy is the main cause of rickets in Ethiopian children.

This study has also documented that rural children are at a higher risk of developing rickets as compared to their urban counterparts which could be mainly due to the traditional beliefs and practices more prevalent in the rural areas. Enhancing behaviour change communication about the benefits of exposing children to sunlight is very important in preventing the prevalence of rickets. Appropriate messages should be designed for the rural community to get rid of harmful traditional practices of not exposing children to sunlight. Additionally nutrition education on the importance of giving calcium rich foods to children (milk and milk products) during infancy and early childhood, especially during second year of life when breast feeding is not adequate source of calcium is recommended.

\section{REFERENCES}

1. Baser, E. and Cakmakci, T. Factors affecting the morbidity of vitamin D deficiency rickets and primary protection. East Afr. Med. J. 1994; 71:358-362.

2. Getaneh, T., Assefa, A. and Tadesse, Z. Rickets and the knowledge and practice of exposure of sunlight in Jimma town. Ethiop. J. Health. Dev. 1998; 12:29-32.

3. Lulseged, S. Severe rickets in a children's hospital in Addis Ababa. Ethiop. Med. J. 1990; 28:175-181.

4. Salimpour, R. Rickets in Tehran. Arch Dis. Child. 1975; 50:63-66.

5. Muhe, L., Lulseged, S., Mason, K. E. and Simoes, E.A.F. Case control study of the role of nutritional rickets in the risk of developing pneumonia in Ethiopian children. Lancet. 1997; 349:1801 -1804.

6. Nutritional rickets in the risk of developing pneumonia in Ethiopian children. Lancet. 1997; 349:1801-1804.

7. Reddv, V. and Lamb, W. H. Nutritional rickets. In Stanfield P. Bructon It Chan X4, Parkill Waterston T, editors. Diseases of children in subtropics and tropics. 4th Ed. Edward Amold. 1991; 376-379.

8. Aust-Kettis, A, Bjomesjo E., Mannheimer E. et al. Rickets in Ethiopia. Ethiop. Med. J. 1965; 3:109-121.

9. Eslietu, M. Analysis of paediatric admissions to Jimma hospital pediatric ward: a 3 year retrospective study. Bull JIHS 1994; 4:1-11.
10. Aetiology of nutritional rickets: geographic variations (commentary). J Paediat. 1996; 128:600-601.

11. Kloos, G. and Ahmed, Z. The ecology of health and disease in Ethiopia. West view press. Boulder, Sanfransisco Oxford. 1993; 96.

12. Wills, X. M. Pbillips, J. B., Day, R. C. and Bateman, E. C. Phytic acid and nutritional rickets in immigrants. Lancet. 1972; 1:771-773.

13. Kooh, S.W., Fraser, D., Reilly, B. J., et al. Rickets due to calcium deficiency. N. England. J. Med. 1977; 297:1264-1266.

14. Clenients, M. Johnson, L.and Fraser, D. R. A new mechanism for induced vitamin D deficiency in calcium deprivation. Nature 1987; 325:62-65.

15. Okonofua, F., Gill, D. S., Alabi, Z. O., Thomac, M., Bell, Y. L. and Dandona, P. Rickets in Nigerian children: a consequence of calcium malnutrition. Metabolism 1991; 40:209-213.

16. Oginni, I. N., Worsfold, M., Ovelami, O. A. et al. Aetiology, of rickets in Nigerian children. J. Paediat. 1996; 128:692-624.

17. Pettifer, J. I., Ross, F. P., Wang, J. et al. Rickets in children of rural origin in South Africa: Is low dietary calcium a factor? J. Paediatric 1978; 92:320-324.

18. Thacher, T. D., Pettifor, J. M. and Fischer, P. R. "D or not D" - that is the question. J. Pediatr. 1997; 130:332-333.

19. David L. Common vitamin D-deficiency rickets. In: Glorieux $\mathrm{FH}$, ed. Rickets. Vol. 21 of Nestle nutrition.

20. Thacher, T. D., Glew, R. H., Isichei, C. O. et al. Rickets in Nigerian children: response to calcium supplementation. J. Trop. Pediatr. 1999; 45:202-207.

21. Oginni, L. M., Sharp, C. A., Worsfold, M. et al. Healing of rickets after calcium supplementation. Lancet. 1999; 353:296-297.

22. Pettifor, J. M., Ross, P., Wang, J., Moodley, G. and CouperSmith, J. Rickets in children of rural origin in South Africa: is low dietary calcium a factor? J. Pediat. 1978; 92:320-324.

23. Tom D., Thachlller, P. R., Fischer, J. M. et al. A Comparison of calcium, vitamin $\mathrm{D}$, or both for nutritional rickets in Nigerian children. Department of Pediatric and Adolescent-Medicine, Mayo Clinic, 200 First St., SW, Rochester, MN 55905, or at fischer.philmayo.edu.

24. American Academy of Pediatrics, Committee on Nutrition. Vitamins: vitamin D. In: Kleinman RE, ed. Pediatric Nutrition Handbook. 4th ed. Elk Grove Village, IL: Amer. Acad.Pedit. 1998; 275-277.

25. M. Holick. Evolution, biological functions, and recommended dietary allowance for Vitamin D, in Vitamin D: Physiology, Molecular Biology, and Clinical Applications, M. Holick, ed. Totawa, NJ: Humana Press, 1999.

26. Makin, H. et al. Vitamin D and its metabolites in human breast milk. Arch. Dis. Child. 1983; 58:750-753.

27. Ala-Houhala, M. 25-Hydroxyvitamin D Levels during breast-feeding with or without maternal or infantile supplementation of Vitamin D. J. Pediat. Gastroent Nutr. 1985; 2:220-226.

28. Holick, M. Environmental factors that influence the cutaneous production of Vitamin D. Amer. J. Clin. Nutr 1995; 61 (suppl.)638S-645S.

29. Brazerol, W. et al. Serial ultraviolet B exposure and serum 25 hydroxyvitamin $\mathrm{D}$ response in young adult blacks and whites: No racial difference. J. Amer Coll. Nutr. 1988; 2:111-118.

30. Ethiopian Health and Nutrition Research Institute(EHNRI). Food composition table for use in Ethiopia Part V, EHNRI: Addis Ababa 1998.

31. Agren, A.and Gibson, R. Food composition table for use in Ethiopia I, EHNRI: Addis Ababa. 